\title{
ANNUAL REPORT 2009
}

\section{The}

\section{Norwegian Renal Registry}

\section{(Norsk Nefrologiregister)}

This report will also be available on:

http://www.nephro.no/registry.html

Correspondence to:

Overlege dr.med Torbjørn Leivestad

Institute of Immunology, Rikshospitalet, N-0027 Oslo, Norway.

Fax: 47- 230735 10. Tel: 47- 23071378.

E-mail: torbjorn.leivestad@rikshospitalet.no 


\section{Preface}

The Norwegian Renal Registry (Norsk Nefrologiregister) was formally constituted in 1994 as collaboration between The Norwegian Renal Association (Norsk Nyremedisinsk Forening) and Rikshospitalet University Hospital, with the latter as the formal owner. National data on renal replacement therapy (RRT) had been collected within The Renal Association since 1980 in a less formalised manner, and the transplant centre had stored data on transplanted patients since the sixties. Further, Norwegian renal units had reported to the ERA-EDTA-registry since the late sixties.

During the recent years a process of transition from a pure epidemiological registry into a quality-oriented registry has been initiated. Some results from this have appeared in the latest annual reports. With the present way of collecting and processing quality data, they cannot be collected in time to be included in the annual report. Selected data will be included in the next report; others will be theme for quality-seminars and special reports.

\section{National organisation and policy}

Norway has 4.825 mill. inhabitants (July 2009) and 19 counties with populations ranging from 72500 to 580000. Each county, except one, has a central renal unit and some have two, further some have satellite units run in close contact with the central unit. There is only one transplant centre (two during 1963-83). Pre-transplant work-up, as well as post-transplant follow-up beyond 3 months, is handled by the county-centres.

The county-centres are responsible for reporting data from day 1 on all patients receiving renal replacement therapy (RRT) for chronic renal failure within their area. Treatment of acute renal failure is not reported unless the failure turns out to be irreversible, in which case the whole treatment period is included. Minor changes of treatment modality, e.g. from HD to HDF or between CAPD and APD, are not reported. Similarly, temporary changes to HD for PD-patients are not reported. At intervals, cross-checking for unreported deaths is performed against official census data.

Transplantation has always been considered the treatment of choice, if possible with a living related donor. Since 1984, also unrelated donors have been used. Acceptance criteria for transplantation have been wide, strict age limits have not been applied. Over time, an increasing number of non-transplantable patients have also been offered life-long dialysis.

Incidence and prevalence calculations in this report are based on the national population data from July 2009, although this in some instances may be slightly misleading since population changes have not been uniform in all counties during the period.

\section{Incidence figures for $\mathbf{2 0 0 9}$}

During 2009 a total of 561 new patients (in 2008: 533) entered renal replacement therapy (RRT), i.e. 116.3 per mill. inhabitants.

A majority of 380 (67.7\%) were males and 181 (32.3\%) females. Median age at start was 65.2 years, mean 62.7 years, ranging from 3 days to 90.4 years.

Tabulated by first mode of treatment, and age at start of treatment:

\begin{tabular}{|l|c|c|c|c|c|c|c|c|c|c|c|}
\hline & $<15$ & $15-24$ & $25-34$ & $35-44$ & $45-54$ & $55-64$ & $65-74$ & $75-84$ & $85+$ & Total & in \% \\
\hline HD & 0 & 8 & 8 & 29 & 35 & 80 & 86 & 103 & 16 & 365 & 65.1 \\
\hline PD & 2 & 2 & 1 & 6 & 12 & 30 & 32 & 28 & 5 & 118 & 21.0 \\
\hline TX & 6 & 4 & 5 & 14 & 18 & 18 & 13 & 0 & 0 & 78 & 13.9 \\
\hline Total & 8 & 14 & 14 & 49 & 65 & 128 & 131 & 131 & 21 & 561 & 100 \\
\hline in \% & 1.4 & 2.5 & 2.5 & 8.7 & 11.6 & 22.8 & 23.4 & 23.4 & 3.7 & 100 & \\
\hline
\end{tabular}


At start of treatment, 369 (65.8 \%) were considered by their nephrologist to be a potential candidate for transplantation, while 192 (34.2 \%) were accepted for life-long dialysis (the latter constituting $43 \%$ of those starting with HD and $30 \%$ of those starting PD).

Among patients starting dialysis in 2009, $73.9 \%$ had been under control by the renal unit for at least four months, while $26.1 \%$ were previously unknown.

\section{Incidence data: Changes 1980-2009}

\section{New patients in RRT \\ by year of start \& first mode of treatment}



TL $07 / 10$

\section{Incidence data: Age at start}

\section{Age of new patients in RRT \\ Percentiles and range, by year of start}



TL $07 / 10$ 
Since registration started in 1980 there has been a continuous shift in patient age. Both the maximum and the median age at start of RRT have increased. Also the 5-percentile and 95percentile values (i.e. including the majority of patients) have increased with a similar number of years. But also smaller children have been accepted; the youngest ever started PD in 2009 at age 3 days. Eight children below 15 years started RRT in 2009; after the peak number of 12 in 2005 we seem to be back to the previous range; between two and ten per year.

\section{Incidence data: Primary renal disease}

\begin{tabular}{|c|c|c|c|c|c|c|}
\hline & $1980-89$ & $1990-94$ & $1995-99$ & $2000-04$ & $2005-08$ & 2009 \\
\hline Glomerulonephritis & $35 \%$ & $31 \%$ & $24 \%$ & $18 \%$ & $19 \%$ & $17 \%$ \\
\hline Pyelo/interstitial nephr. & $16 \%$ & $11 \%$ & $11 \%$ & $11 \%$ & $9 \%$ & $11 \%$ \\
\hline Polycystic diseases & $10 \%$ & $9 \%$ & $9 \%$ & $9 \%$ & $8 \%$ & $9 \%$ \\
\hline Diabetic nephropathy & $13 \%$ & $12 \%$ & $11 \%$ & $15 \%$ & $15 \%$ & $18 \%$ \\
\hline Amyloidosis & $6 \%$ & $6 \%$ & $4 \%$ & $3 \%$ & $2 \%$ & $1 \%$ \\
\hline Vascular/hypertensive & $7 \%$ & $18 \%$ & $25 \%$ & $29 \%$ & $31 \%$ & $32 \%$ \\
\hline Immune/systemic & $5 \%$ & $4 \%$ & $5 \%$ & $4 \%$ & $4 \%$ & $3 \%$ \\
\hline Kidney tumour & $1 \%$ & $1 \%$ & $1 \%$ & $1 \%$ & $2 \%$ & $2 \%$ \\
\hline Myelomatosis & $2 \%$ & $2 \%$ & $2 \%$ & $3 \%$ & $3 \%$ & $1 \%$ \\
\hline Other defined & $4 \%$ & $4 \%$ & $3 \%$ & $4 \%$ & $4 \%$ & $3 \%$ \\
\hline Unknown & $3 \%$ & $3 \%$ & $4 \%$ & $4 \%$ & $4 \%$ & $2 \%$ \\
\hline $\mathrm{N}:$ & 2019 & 1418 & 1817 & 2149 & 1994 & 561 \\
\hline
\end{tabular}

The main change over time has been an increase of vascular/hypertensive nephropathy and a relative reduction of glomerulonephritis. Whether this only reflects changed coding practice or a true shift is not known. Amyloidosis also seems reduced over time.

Diabetic nephropathy has contributed 10-15\% per year. Until 1995 sub-classification was not reliably registered. In 2009, 32 were registered as having Type I and 71 as Type II diabetes, 75 patients with other types of primary renal disease were recorded as having diabetes as a co-morbid factor (two were Type I and 73 Type II), thus 32\% of new patients were diabetics.

The time from onset of diabetes to start of RRT differed considerably. For the 32 with Type I diabetes the mean time was 33.7 years, for the 71 with Type II diabetic nephropathy the mean time was 17.0 years. Type II diabetics judged to have a primary renal disease other than diabetic nephropathy in mean had 10.4 years of pre-RRT diabetes duration.

Cardiovascular disease is often present at start of RRT. Coronary heart disease was reported in 156 (28\%). Left ventricular hypertrophy was reported in 156 (28\%). Cerebrovascular disease was reported in 73 (13\%) and peripheral atherosclerotic disease in 101 patients (18\%).

\section{Prevalence data: Status by 31.dec. 2009.}

By the end of 2009, 4069 patients in Norway received renal replacement therapy, i.e. 843.2 per million inhabitants. This represents an increase of 181 patients or $4.6 \%$ since 2008. Gender: $64.7 \%$ males and $35.3 \%$ females.

Median age by the end of the year was 60.1 years, mean 58.1 years and range 0.2 - 95.8 years.

Tabulated by last mode of treatment, and age by end of 2009: 


\begin{tabular}{|l|c|c|c|c|c|c|c|c|c|c|c|}
\hline & $<15$ & $15-24$ & $25-34$ & $35-44$ & $45-54$ & $55-64$ & $65-74$ & $75-84$ & $85+$ & Total & in \% \\
\hline HD & 0 & 8 & 27 & 63 & 104 & 197 & 239 & 279 & 71 & 988 & 24.3 \\
\hline PD & 5 & 4 & 2 & 17 & 23 & 42 & 53 & 67 & 15 & 228 & 5.6 \\
\hline TX & 36 & 81 & 180 & 464 & 574 & 743 & 569 & 190 & 16 & 2853 & 70.1 \\
\hline Total & 41 & 93 & 209 & 544 & 701 & 982 & 861 & 536 & 102 & 4069 & 100 \\
\hline In \% & 1.0 & 2.3 & 5.1 & 13.4 & 17.2 & 24.1 & 21.2 & 13.2 & 2.5 & 100 & \\
\hline
\end{tabular}

\section{Renal replacement therapy in Norway}

Prevalence of treatment modes in 1990, -95, 2000, -05 \& -09 .

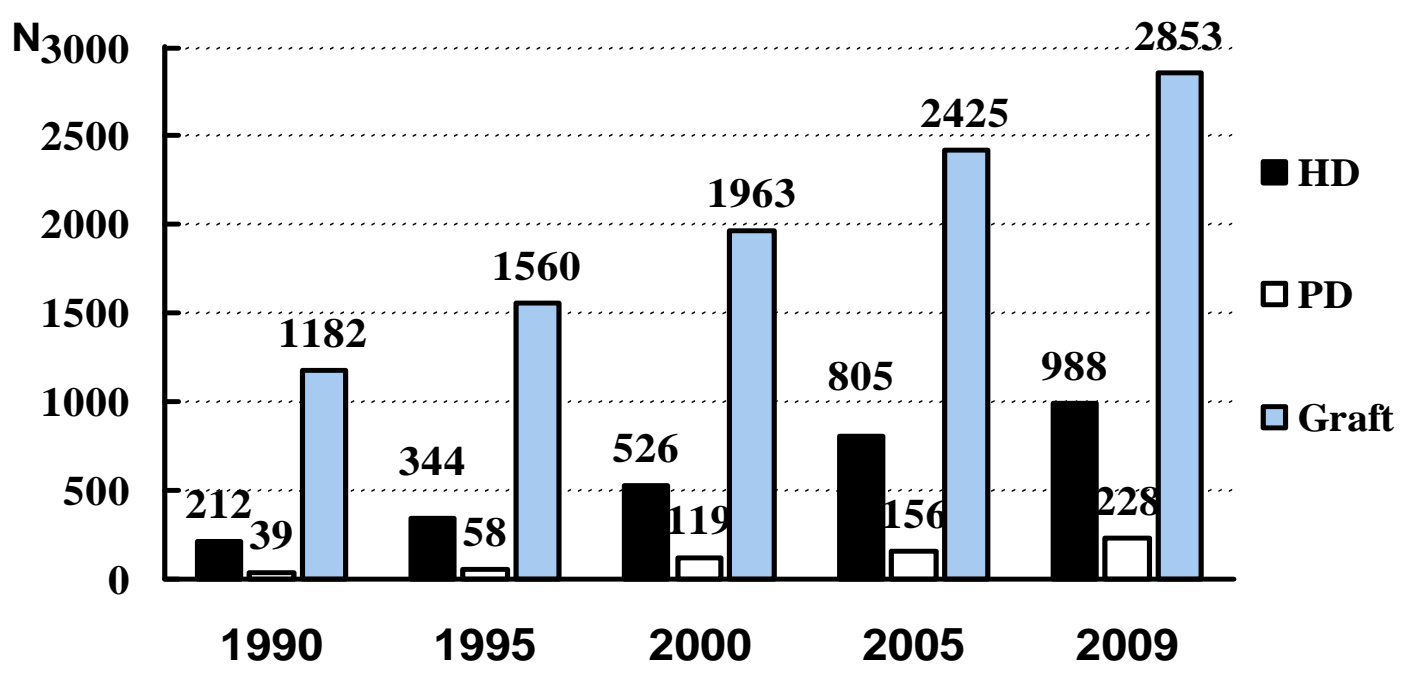

TL $07 / 10$

\section{Transplantation and waiting lists:}

A total of 292 renal transplants were performed at Rikshospitalet University Hospital in 2009, i.e. 60.5 per million inhabitants. In 104 (36\%) the graft came from a living donor (LD), 27 of those were biologically unrelated to the recipient (20 were spouses). Among the LD-graft recipients 44 out of 92 first graft recipients were grafted pre-emptively, five out of 12 re-graft recipients did not receive dialysis. 188 patients received a deceased donor (DD) graft, 35 out of the 156 first graft recipients were pre-emptively transplanted (22\%), while four out of 32 had a re-graft without entering dialysis. There were 248 first grafts (92 LD and 156 DD), 38 were second grafts (10 LD, 28 DD), six third grafts (2 LD, 4 DD). Simultaneous kidney + pancreas transplantation was performed in 16. Among patients with a functioning kidney graft three received one or more doses of isolated Langerhans Islet cells.

In principle, transplantation is offered to all patients considered to profit from it, with no strict upper or lower age limit. The age of the 156 first DD-graft recipients in 2009 ranged from 14 to 80 years, with a mean age of $57 \mathrm{y}$. Out of these, $33 \%$ were above the age of 65 and $4 \%$ were 75 or older. The 92 recipients of a first LD-graft were from 1 to 78 years, mean $46.9 \mathrm{y}$. Regraft recipients $(n=44)$ were from 22 to 81 years, mean $52.1 \mathrm{y}$. 


\section{Renal replacement therapy in Norway Status by end of year - pats. pr mill. inhabitants}



By end 2009, 179 patients (37.1 per mill.) were on the active waiting list for a DD renal graft. This represented a reduction of 13 patients (7\%) since 2008. Among those waiting by Dec.31, median time on the list was 7.5 months. $40 \%$ had waited less than 6 months, $68 \%$ less than one year and only $11 \%$ more than two years. The 188 recipients given a DD-graft in 2009 had a median waiting time of 8 months and a maximum of 74 months at the time of grafting.

Among the 1159 patients in dialysis treatment by Dec.31, 613 (50.5 \%) were for various reasons not considered candidates for a new renal graft.

\section{Quality measures in RRT.}

\section{A: New patients in 2009 - status at start of RRT.}

A total of 561patients started RRT in 2009. Among the 365 starting haemodialysis, the access was via catheter in 276 patients (76\%), while $24 \%$ had AV-fistula (88) or graft (1) as access.

\begin{tabular}{|l|c|c|c|c|}
\hline Status at start of RRT & Total (n:561) & HD (n:365) & PD (n:118) & Tx (n:78) \\
\hline Creatinine (mean) & $614 \mathrm{mmol} / \mathrm{l}$ & 650 & 607 & 456 \\
\hline $\begin{array}{l}\text { GFR (mean), by MDRD } \\
\text { formula }\end{array}$ & $9.5 \mathrm{ml} / \mathrm{min}$ & 8.5 & 10.3 & 13.3 \\
\hline Albumin, mean & $36 \mathrm{~g} / \mathrm{L}$ & 34 & 39 & 43 \\
\hline Haemoglobin, mean & $10.7 \mathrm{~g} / \mathrm{dL}$ & 10.3 & 11.3 & 11.8 \\
\hline Haemoglobin - \% <11 g/dL & $55 \%$ & $67 \%$ & $42 \%$ & $22 \%$ \\
\hline ESA use & $62 \%$ & $60 \%$ & $71 \%$ & $58 \%$ \\
\hline Active D vitamin use & $65 \%$ & $58 \%$ & $76 \%$ & $85 \%$ \\
\hline Statin use & $58 \%$ & $55 \%$ & $64 \%$ & $59 \%$ \\
\hline Not on antihypertensive drugs & $7 \%$ & $9 \%$ & $2 \%$ & $10 \%$ \\
\hline Using >2 antihypertensive drugs & $56 \%$ & $55 \%$ & $64 \%$ & $46 \%$ \\
\hline
\end{tabular}

As might be anticipated, pre-emptively transplanted patients had a somewhat lower serum creatinine, thus higher GFR, and a higher haemoglobin and albumin than those starting dialysis. Among patients known less than four months, $82 \%$ had haemoglobin $<11 \mathrm{~g} / \mathrm{dL}$.

While pre-emptive transplantation is considered the best initial RRT, HD by catheter may be considered the poorest alternative. In the following figure, individual centres are ranged by 

figures).

\section{Initial RRT 2009, by centre.}



\section{B: Prevalent RRT patients by end of 2008}

Once a year, the registry collects data on a set of treatment details and quality measures for all patients in RRT. Data collection for the treatment year 2009 is not yet completed; selected data will be part of the next annual report.

Status data were requested for all dialysis patients who had been on RRT for at least one month by 31.Dec.2008; the return rate was $99.8 \%$. Similarly, data were requested for all patients with a functioning graft except those transplanted during September to December 2008. The return rate was above $98 \%$.

\section{"Dialysis dose":}

Due to a lack of standardisation, the registry has not been able to collect reliable data on given dialysis dose in the form of Kt/V or URR (Urea reduction rate). The number of HD-sessions pr. week, as well as the number of weekly HD treatment hours, is collected. The published European Best Practice Guidelines indicates that: "The standard HD dose should be delivered as 3x4 h. Even if the standards of adequacy such as dose expressed as eKt/V are reached, a minimum time of 3x4 h/week is desirable.” Further, according to the DOPPS report 2006:”On average, each 30-minute increase on haemodialysis (HD) was associated with a 7\% lower RR of mortality."

During 2008 concern was raised by the registry that as much as $23 \%$ of HD-patients received less than three sessions pr week, at one centre this applied to $71 \%$ of their patients. By end of 2008, these figures were somewhat improved, to $20 \%$ and $58 \%$ respectively. One might expect that centres with the longest travel distances would have the highest proportion of patients receiving few HD-sessions. This is clearly not the case.

Nine percent of patients received more than three HD sessions, in two centres this was the case for $25 \%$ of their HD-patients.

As for the weekly treatment time, $32 \%$ received less than 12 hours/week. There was a marked centre variation, from 0 and up to $60 \%$ received less than the recommended number 


\section{HD-sessions/week, by center. 2008}



There are probably several different factors contributing to this widespread under-treatment, as compared to the guidelines. Patients may oppose to spending more hours in dialysis than they feel necessary. Locally, there may also be a lack of resources. Nevertheless, the data still give reasons for concern.

HD-access: $54 \%$ of prevalent HD patients had a functioning AV-fistula; additionally $1 \%$ had a graft, while the remaining $45 \%$ were dialysed via catheter. The methods of access varied considerably between the various centres, as shown below (same codes as above):

\section{HD-access, by center, end of 2008}



The widespread use of catheter-access may have negative consequences. There have been several reports demonstrating increased mortality related to catheter use, both in mortality 
from infections and all-cause mortality. Several centres seem to need to revise their policy in this respect.

Anaemia control: Among prevalent dialysis patients, $30 \%$ had an Hgb level below the recommended range of 11-12 g/L, while $39 \%$ were above. ESA was used by $90 \%$, including most patients with Hgb $>12$. In general, transplanted patients had higher Hgb; only $7 \%$ of them were using ESA.

\begin{tabular}{|l|c|c|c|c|c|c|}
\hline & $<9 \mathrm{~g} / \mathrm{L}$ & $9-11 \mathrm{~g} / \mathrm{L}$ & $11-12 \mathrm{~g} / \mathrm{L}$ & $12-13 \mathrm{~g} / \mathrm{L}$ & $13-15 \mathrm{~g} / \mathrm{L}$ & $>15 \mathrm{~g} / \mathrm{L}$ \\
\hline $\mathrm{HD}$ & $3 \%$ & $29 \%$ & $31 \%$ & $25 \%$ & $11 \%$ & $0.5 \%$ \\
\hline $\mathrm{PD}$ & $1 \%$ & $19 \%$ & $31 \%$ & $29 \%$ & $19 \%$ & $2 \%$ \\
\hline Tx & $0.3 \%$ & $8 \%$ & $16 \%$ & $21 \%$ & $41 \%$ & $14 \%$ \\
\hline
\end{tabular}

Comparing the dialysis centres, the best one had $55 \%$ of their dialysis patients within the range $11-12 \mathrm{~g} / \mathrm{L}$; the poorest had only $14 \%$ within that range.

Blood pressure control: A majority of patients use antihypertensive medication; only $21 \%$ of dialysis patients and $18 \%$ of patients with functioning graft do not. Among dialysis patients, $19 \%$ use 3 or more antihypertensive drugs; this is also the case in $16 \%$ of the transplanted.

\begin{tabular}{|l|c|c|c|}
\hline & BP $\leq 130 / 80$ & BP 131-140/81-90 & BP $>140$ and/or $>90$ \\
\hline Dialysis patients & $52 \%$ & $3 \%$ & $44 \%$ \\
\hline Transplanted patients & $67 \%$ & $10 \%$ & $23 \%$ \\
\hline
\end{tabular}

Also here a considerable variance between centres could be seen. In the best performing dialysis centre $89 \%$ of patients had BP $130 / 80$ or lower, while others only obtained such control in 21\%. The fraction of well controlled Tx-patients varied between $92 \%$ and $49 \%$.

Phosphate control: $84 \%$ of dialysis patients were reported to use phosphate binders, 23\% using calcium-containing, $36 \%$ using calcium-free and $25 \%$ using a combination of the two. Serum phosphate was below $1.8 \mathrm{mmol} / \mathrm{L}$ in $64 \%$; the control was better among those not using binders. It also seemed that control was poorest among those given the combination.

\section{Death in RRT:}

A total of 381 patients in renal replacement therapy died during 2009, i.e. $8.6 \%$ out of the 4453 persons at risk. Among these, 66\% were males and 34\% females. Median age at death was 73 years, mean 71 years, and the range 21-95 years. Median time from start of RRT until death was 34 months, with a range spanning from one month to 36 years.

The final mode of treatment was HD for 229 patients and PD for 43, while 109 died with a more or less well-functioning graft. One died within two months after graft loss; thus 110 deaths were termed 'TX-related'. Dialysis treatment was terminated and followed by death in 53 patients; in 17 of those the patient refused further treatment.

Cardiac complications (29\%) and infections (24\%) were the most frequent causes of death, followed by vascular complications (15\%), and malignant tumours (15\%).

\section{Regional differences within Norway.}

\section{Incidence:}

During all the years since data collection was started, the number of patients reported has differed substantially between centres, also after correction for population size. Further the first mode of treatment (HD, PD or pre-emptive transplant) for new patients differs considerably. In the following figure, patients were grouped by county of domicile at RRTstart and the incidences were calculated as a yearly mean for the five-year period 2005-2009: 


\section{RRT in Norway 2005-2009}

\section{Mean yearly incidence, by first treatment and county}



As appears, the mean yearly incidence of RRT-start varied from 75 to 142 pr. million, with Rogaland having the lowest and Buskerud the highest mean incidence. With the rather small population in most counties, figures may be expected to change from year to year, but over years there has been a lower incidence in the west-coast counties.

There is national consensus that pre-emptive transplantation is preferable. Looking solely at 2009-data (i.e. not the figure above), this was achieved in more patients than earlier years, constituting $14 \%$ of all. In the individual counties the numbers are small, but this figure ranged from 4\% to impressive 46\% (Aust Agder).

Efforts are also done to increase the use of PD. Still in some counties PD is rarely used, in others up to $40 \%$ of new patients have this as first treatment mode. $65 \%$ received HD as first treatment mode, in the counties this ranged from $39 \%$ to $86 \%$.

The proportion of the new dialysis patients in 2009 who started RRT without having been known by the renal unit for at least 4 months was $26 \%$, with wide variations between centres; from $10 \%$ and up to $57 \%$. In the majority of these cases the diagnosis would imply that renal failure has developed gradually over years. These figures seem not to have improved significantly; thus in most counties there seems to be need for improved co-operation with the primary health service in order to achieve more early referrals.

We have previously reported marked centerwise differences in the age distribution of incident patients. In 2009 mean age of new patients in the different counties ranged from 56 to 70 years. The huge variation in age-specific incidence between counties was latest shown in the 2004 report.

\section{Prevalence:}

Again, the data demonstrate great differences between the counties. In all counties the majority of patients have a functioning graft, constituting from $63 \%$ to $76 \%$ of the total RRTpopulation. The dialysis prevalence ranges from 187 to 335 per mill. inhabitants in the counties, indicating considerable differences in workloads and costs. In some counties, three 
out of four dialysis patients are not considered candidates for a new graft, in others this applies to one out of three. But counties with high dialysis prevalence do not necessarily have a high prevalence of 'non-transplantable' patients.

\section{RRT in Norway by end of 2009 Prevalence, by treatment mode and county}



\section{Concluding remarks:}

The 2009 figures again showed a rising incidence of RRT, indicating that the situation in Norway is still not in line with other European countries where RRT incidence seems to have levelled off (Kramer A \& al, Nephrol Dial Transpl 2009; 24: 3557-3566). With an increased survival rate (as demonstrated in the 2004-report), a markedly increased prevalence of RRTpatients can nevertheless be expected over the coming years. Marked county differences may also indicate that in some areas there may still be under-treatment.

The year 2009 gave a new all-time high transplantation rate. Yet, the dialysis population grew with 5\% from 2008. Even with an officially declared aim of doubling the donation rate, it is not obvious that the supply of organs for transplantation will rise further. The number of patients in dialysis will probably still rise and will constitute an increasing proportion of the RRT-population. Unless home-based treatment (i.e. CAPD and home-HD) is radically expanded, the capacity of the hospital HD-units will need to be further increased.

Comparing our data on the quality of RRT with updated international guidelines, it seems that there still is room for quality improvement. Registry data will over the coming years be used for comparisons between the centres to a greater extent than has been the case. Hopefully, the registry can in this way be an instrument for improved RRT quality and thus benefit the patients who have consented to have their data included in the registry. 


\section{ESRD 2009 in Norway \\ Patient dynamics}

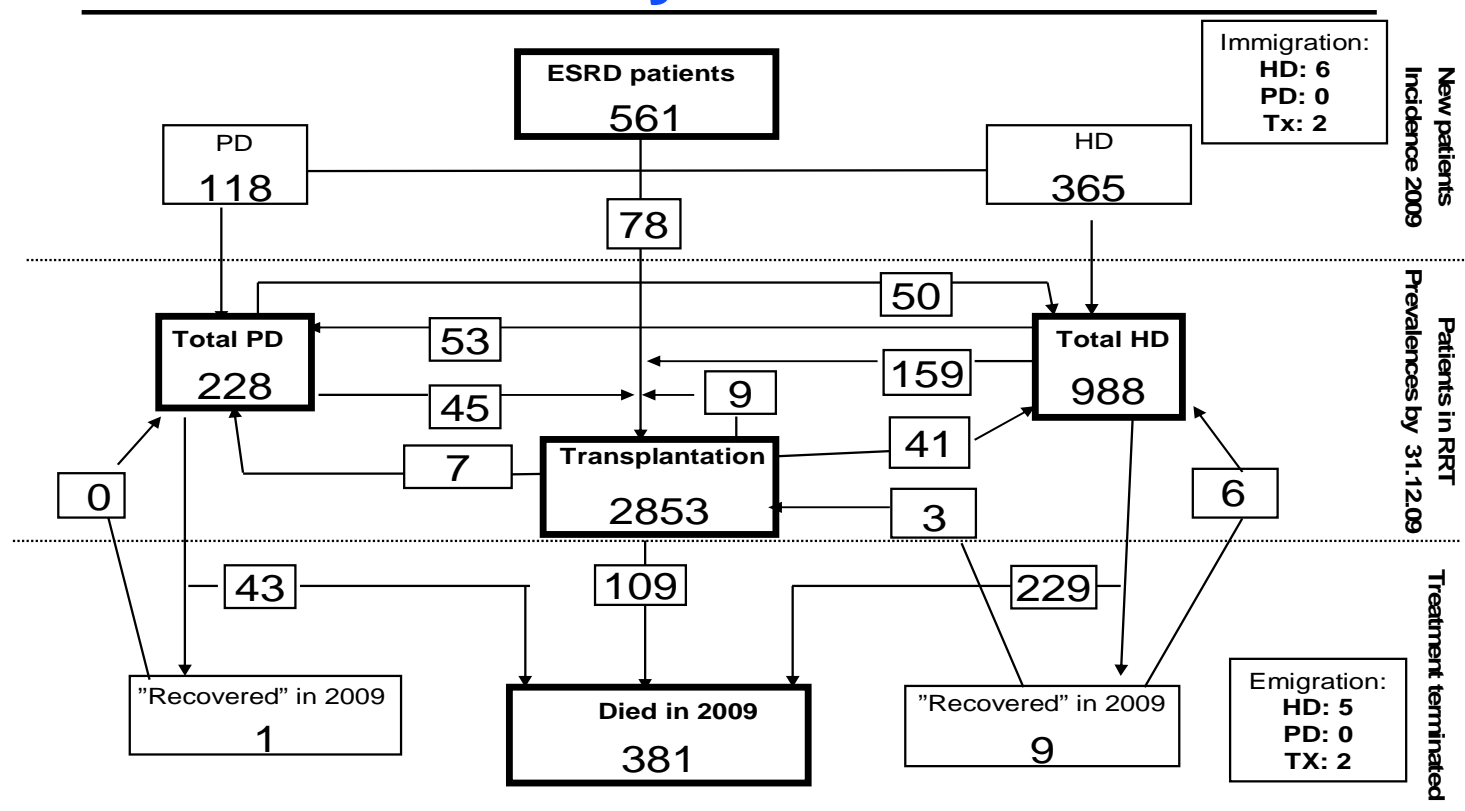

\begin{tabular}{|c|c|c|c|c|c|c|c|c|c|c|c|c|c|c|c|}
\hline & & New & pat in & RRT $2 C$ & & Pat. & in $\mathrm{RR}$ & by $1 / 1$ & 2010 & Dialyses & etc. 20 & & Died 2 & 2009 & \\
\hline & 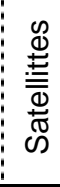 & $\begin{array}{l}\text { 늠 } \\
\text { 옹 } \\
\text { 오 }\end{array}$ & 음 & 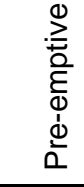 & $\begin{array}{l}\bar{\pi} \\
\stackrel{0}{0} \\
\vdash\end{array}$ & 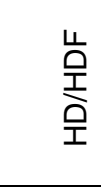 & Q & $\frac{\frac{5}{\pi}}{\frac{\pi}{0}}$ & $\begin{array}{l}\bar{\pi} \\
\stackrel{0}{0} \\
\end{array}$ &  & 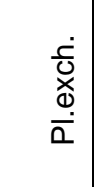 & $\begin{array}{l}\bar{\Phi} \\
\stackrel{\Phi}{\Xi}\end{array}$ & $\frac{\stackrel{\pi}{\frac{\pi}{0}}}{\frac{\pi}{\Delta}}$ & $\begin{array}{l}\overrightarrow{\tilde{\sigma}} \\
\stackrel{0}{\dot{x}} \\
\stackrel{+}{*}\end{array}$ &  \\
\hline Tromsø & 4 & 22 & 8 & 2 & 32 & 39 & 19 & 122 & 180 & 6222 & 107 & 0 & 8 & 2 & 28 \\
\hline Harstad & & 5 & 0 & 1 & 6 & 10 & 0 & 39 & 49 & 1514 & 0 & 0 & 3 & 2 & 8 \\
\hline Bodø & 7 & 21 & 9 & 3 & 33 & 52 & 21 & 124 & 197 & 8456 & 17 & 158 & 19 & 5 & 41 \\
\hline Levanger & 4 & 14 & 3 & 2 & 19 & 30 & 3 & 66 & 99 & 4929 & 16 & 0 & 9 & 3 & 21 \\
\hline Trondheim & 4 & 16 & 7 & 9 & 32 & 57 & 16 & 192 & 265 & 10543 & 259 & 252 & 17 & 9 & 45 \\
\hline Kristiansund $\mathrm{N}$ & 1 & 5 & 0 & 0 & 5 & 20 & 0 & 16 & 36 & 2939 & 0 & 0 & 10 & 4 & 10 \\
\hline Ålesund & 1 & 12 & 7 & 1 & 20 & 40 & 8 & 115 & 163 & 5865 & 39 & 0 & 5 & 4 & 36 \\
\hline Førde & 2 & 12 & 0 & 1 & 13 & 21 & 0 & 50 & 71 & 3106 & 5 & 47 & 7 & 1 & 16 \\
\hline Bergen & 1 & 24 & 5 & 4 & 33 & 70 & 15 & 231 & 316 & 11104 & 169 & 66 & 16 & 9 & 38 \\
\hline Stord/Hauges. & 1 & 15 & 1 & 1 & 17 & 31 & 4 & 64 & 99 & 4971 & 0 & 51 & 9 & 1 & 18 \\
\hline Stavanger & & 11 & 7 & 3 & 21 & 51 & 8 & 175 & 234 & 7755 & 34 & 52 & 14 & 8 & 31 \\
\hline Kristiansand S & 1 & 13 & 1 & 4 & 18 & 39 & 7 & 98 & 144 & 6484 & 38 & 0 & 10 & 5 & 30 \\
\hline Arendal & & 5 & 2 & 6 & 13 & 24 & 4 & 72 & 100 & 4225 & 0 & 39 & 7 & 2 & 18 \\
\hline Skien & 2 & 11 & 3 & 6 & 20 & 43 & 9 & 107 & 159 & 6235 & 5 & 86 & 4 & 2 & 21 \\
\hline Tønsberg & & 15 & 11 & 6 & 32 & 31 & 17 & 144 & 192 & 4447 & 93 & 49 & 16 & 7 & 21 \\
\hline Hønefoss & 1 & 13 & 0 & 2 & 15 & 31 & 0 & 44 & 75 & 3941 & 0 & 0 & 7 & 1 & 20 \\
\hline Drammen & 1 & 20 & 4 & 5 & 29 & 40 & 9 & 142 & 191 & 5354 & 7 & 0 & 12 & 8 & 17 \\
\hline Lillehammer & 2 & 10 & 8 & 2 & 20 & 36 & 18 & 110 & 164 & 5930 & 14 & 0 & 10 & 5 & 33 \\
\hline Elverum & 1 & 16 & 10 & 4 & 30 & 43 & 13 & 100 & 156 & 5798 & 0 & 13 & 12 & 3 & 32 \\
\hline Fredrikstad & 1 & 17 & 7 & 2 & 26 & 51 & 9 & 163 & 223 & 8331 & 5 & 0 & 20 & 7 & 20 \\
\hline AHUS & & 17 & 7 & 0 & 24 & 75 & 16 & 170 & 261 & 11002 & 0 & 0 & 10 & 10 & 39 \\
\hline Aker & & 18 & 0 & 1 & 19 & 25 & 0 & 2 & 27 & 2559 & 0 & 0 & 9 & 0 & 16 \\
\hline Ullevål & & 34 & 17 & 9 & 60 & 99 & 32 & 303 & 434 & 14482 & 52 & 0 & 24 & 3 & 45 \\
\hline $\mathrm{RH}$ & & 19 & 1 & 4 & 24 & 30 & 0 & 204 & 234 & 5361 & 162 & 87 & 13 & 9 & 9 \\
\hline SUM & & 365 & 118 & 78 & 561 & 988 & 228 & 2853 & 4069 & 151553 & 1022 & 900 & 271 & 110 & 613 \\
\hline \# Pr. mill inh. & & 75,6 & 24,5 & 16,2 & 116,3 & 204,7 & 47,2 & 591,2 & 843,2 & $i e .+5,9 \%$ & & & & & 127,0 \\
\hline$\%$ of total & & 65,1 & 21,0 & 13,9 & 100,0 & 24,3 & 5,6 & 70,1 & 100,0 & from 2008 & & & & & 50,4 \\
\hline
\end{tabular}

